\title{
Os desafios na prática do pacto nacional pela alfabetização na idade certa
}

\author{
Challenges in practice the national pact literacy at the right age \\ Claudia Maria dos Santos Machado ${ }^{2}$, Sebastião Ailton da Rosa Cerqueira Adão ${ }^{3}$ \\ ${ }^{2}$ Graduada em Ciências Biológicas, Universidade Federal do Pampa, Campus São Gabriel \\ Claudiapbid@gmail.com \\ ${ }^{3}$ Professor Adjunto, Universidade Federal do Pampa, Campus Santana do Livramento \\ sebacerqueira@hotmail.com
}

\begin{abstract}
RESUMO
O Pacto Nacional pela Alfabetização na Idade Certa aprovado em 2012, busca contribuir para a alfabetização de todas as crianças até os oito anos de idade, ao final do 3a ano do ensino fundamental. O Ministério da Educação em 2013 passa a contemplar ações que contribuam para a alfabetização em linguagem e matemática, apresentando também como uma das metas principais, a formação dos professores para este novo momento. Este artigo teve como objetivo caracterizar os desafios enfrentados por professores do $1^{\circ}$ ao $3^{\circ}$ Ano da Escola Estadual de Ensino Médio João Pedro Nunes do município de São Gabriel/RS. Para desenvolver este estudo, foram realizadas entrevistas semi estruturadas e aplicados questionários abordando mais especificamente a não retenção, ludicidade, interdisciplinaridade e a importância da participação dos pais na educação dos filhos na escola. Diante dos resultados obtidos acredita-se que alguns professores precisam rever suas práticas e conceitos em relação a estas questões, sugere-se que sejam abordadas com ênfase na formação continuada dos professores alfabetizadores. Para a escola sugere-se a elaboração de estratégias que incentivem a participação da família, a fim de que esta cumpra efetivamente seu papel enquanto base da formação de qualquer criança.
\end{abstract}

Palavras-chave: PNAIC; Interdisciplinaridade; Ludicidade; Não Retenção; Escola; Família.

\section{ABSTRACT}

The National Literacy Pact at the Certain Age approved in 2012 in Brazil, seeks to contribute to the literacy of all children up to the age of eight at the end of the 3rd year of elementary school. The Brazilian Department of Education since 2013 started including actions that contribute to literacy in language and mathematics, as well as presenting a major goal, the training of teachers for this new time. This article aimed to characterize the challenges faced by teachers from 1st to 3rd Years of the State Preparatory High School João Pedro Nunes in São Gabriel / RS. To develop this study, questionnaires, semi-structured interviews were conducted and applied addressing specifically the nonwithholding, playfulness and interdisciplinary. Based on the results believed that some teachers need to review their practices and concepts regarding these issues, it is suggested steps to tackle with emphasis on continued training of literacy teachers. It is suggested that the school develop strategies that encourage family participation, to enable it to effectively fulfill its role as the basic training of any child.

Keywords: PNAIC; Interdisciplinarity; Playfulness; No Retention; School; Family. 


\section{INTRODUÇÃO}

O sistema educacional brasileiro desde a criação do Ministério da Educação em 1930 vem passando por constantes mudanças em busca da qualidade do ensino e da aprendizagem. A partir de 1961 com a aprovação da primeira LDB, os estados e municípios ganham mais autonomia, o sistema de ensino deixa de ser um modelo centralizado e continua sofrendo alterações ao longo dos próximos 55 anos, entre as quais destaca-se a criação do Pacto Nacional pela Alfabetização na Idade Certa em 2012.

No Programa Internacional de Avaliação de Estudantes (PISA) de 2012, o Brasil ocupou a 55 posição no ranking da leitura, e $58^{\underline{a}}$ e $59^{a}$ em matemática e ciências, respectivamente, não apresentando um bom desempenho, considerando o número de 65 países participantes. A meta do Ministério da Educação é melhorar estes resultados, investindo no alicerce da educação básica, ou seja, nos primeiros anos do ensino fundamental. A proposta é que todas as crianças estejam alfabetizadas até os oito anos de idade, ao final do $3^{o}$ ano de ensino fundamental, orientando também para a não retenção neste ciclo.

Partindo do pressuposto que o objetivo da educação não está condicionado a atingir melhores índices, pois estes são conseqüências, a não retenção nos três primeiros anos, tem causado preocupação entre os docentes, chegando a gerar aspectos contraditórios na abordagem deste tema, principalmente quando a retenção esta relacionada à inclusão, pois alguns reconhecem o direito do incluso de estar numa classe regular, mas alegam que não foram preparados e não dispõem de materiais didáticos apropriados para atendê-los. Sendo assim surge uma questão sobre a não retenção: A não retenção visa melhorar os índices da educação ou o sucesso no aprendizado dos alunos?

Muitos pesquisadores afirmam que a retenção traz conseqüências negativas aos discentes, gerando sensações de incapacidade, insucesso e desmotivação, o que pode ocasionar a evasão por sentirse excluído do processo de escolarização. Esta situação envolve geralmente alunos de inclusão, fato este que preocupa os docentes, pois o PNAIC oferece um caderno especial para a educação inclusiva, mas não considera que a maioria dos docentes trabalha sozinho na sala de aula, com um numero excessivo de alunos, o que impossibilita um atendimento mais individualizado, para acompanhar o ritmo de aprendizado de cada um.

Outro fator preocupante é a relevância dada à interdisciplinaridade pelo programa, visto que os cadernos de formação oferecidos contemplam somente as disciplinas de matemática e língua portuguesa, muito embora no caderno de apresentação, ela seja citada como uma ação pedagógica importante no processo de aprendizado.

Sabe-se que o desempenho do docente ainda é avaliado quantitativamente, faz-se necessário provocar a reflexão de pais e professores sobre as mudanças que ocorreram. A estrutura social e cultural é diferente, e isso requer mudanças no comportamento das instituições família e escola, porque o protagonista desta história não é mais o professor, passou a ser o aluno, e estas instituições são as responsáveis pela atuação deste na sociedade, e para isso precisam estar em consonância.

O PNAIC surge como mais um desafio a ser enfrentado por toda a comunidade escolar, pois as mudanças atingem a todos. Diante dessas perspectivas, a presente pesquisa pretende caracterizar os desafios enfrentados pelos professores na implantação deste programa na Escola de Estadual de Ensino Médio João Pedro Nunes de São Gabriel/RS. Adicionalmente, as práticas do PNAIC são relacionadas com a interdisciplinaridade, o lúdico, a não retenção e a importância da participação dos pais na educação dos filhos na escola.

Em termos teóricos, espera-se que os exemplos e resultados obtidos nesta pesquisa sirvam como fio condutor para novas ações, tanto por parte da família que tem um papel primordial e intransferível 
na construção dos valores sociais, como também nos professores que enfrentam novos desafios com o PNAIC, que requer nova postura na suas práticas, agindo com especificidade para o primeiro ciclo da educação básica, considerando que a interdisciplinaridade e o lúdico são ferramentas essenciais na construção do conhecimento.

\section{FUNDAMENTAÇÃO TEÓRICA}

Diante da perspectiva de que a não retenção, a interdisciplinaridade, o lúdico e a participação da família na escola são elementos essenciais para que o PNAIC obtenha sucesso, serão apresentados nesta pesquisa fundamentos teóricos que confirmam que através destes elementos é possível melhorar o desempenho dos educandos, a fim de contribuir na superação dos desafios enfrentados pelos docentes na prática deste programa.

\section{O Pacto pela Educação no Brasil}

O Pacto Nacional pela Alfabetização na Idade Certa foi aprovado em 2012, vindo a contribuir no cumprimento do Decreto n⿳0 6.094, de 24/4/2007, que define, no inciso II do art. $2^{\circ}$ que todas as crianças até os oito anos de idade, ao final do $3^{\circ}$ ano do ensino fundamental, devem estar alfabetizadas. Implantado em 2013, o governo federal, junto com todos os estados e municípios assumiram este compromisso. O Ministério da Educação passou a contemplar ações, disponibilizando programas, materiais didáticos, referências curriculares e pedagógicas que contribuem para a alfabetização e letramento. Uma das metas principais é a preparação dos docentes para este novo desafio, que aconteceu de forma continuada por meio de um curso presencial de dois anos, com carga horária de 120 horas por ano. A primeira parte do curso, em 2013, foi voltada para a linguagem e a segunda, em 2014, para a matemática.

Este programa aborda a alfabetização não só como a codificação e a decodificação de códigos ou domínio de convenções ortográficas, mas perpassa este contexto, tornando-se mais complexa, abrangendo a leitura e produção de textos. Assim, através da interpretação o aluno poderá alcançar a construção da compreensão, tornando-o um cidadão consciente de sua presença e importância no mundo. O Parâmetro Curricular Nacional da Língua Portuguesa, o PCN (1997, p. 15) afirma:

\footnotetext{
(...) o domínio da língua oral e escrita é fundamental para a participação social efetiva, pois é por meio dela que o homem se comunica, tem acesso à informação, expressa e defende pontos de vista, partilha ou constrói visões de mundo e produz conhecimento. Por isso, ao ensiná-la, a escola tem a responsabilidade de garantir a todos os seus alunos o acesso aos saberes linguísticos, necessários para o exercício da cidadania, direito inalienável de todos.
}

A formação continuada do professor neste programa é muito valorizada, pois dela depende a qualidade do ensino. O profissional que não se atualiza corre o risco de tornar suas práticas defasadas e enfadonhas, pois o perfil dos alunos muda constantemente, requerendo professores criativos, e acima de tudo cientes da sua importância na formação dos cidadãos. 


\section{A Importância da Interdisciplinaridade no Trabalho Docente}

A palavra interdisciplinaridade é muito propalada nos espaços escolares, mas o conhecimento sobre esta prática, na maioria das vezes, fica restrito a um significado, ou seja, todos sabem que é o processo de integração mútua entre as disciplinas e campos de conhecimento, mas não observam que na prática ela deve perpassar seu significado, porque além de integrar as disciplinas, ela tem que considerar e incluir no processo o aluno e todo o contexto no qual ele está inserido. Dessa forma, mesmo não sendo uma prática recente, a interdisciplinaridade ainda é um desafio para muitos professores alfabetizadores, por isso há a necessidade de se buscar a formação continuada, a fim de acompanhar as mudanças e obter bons resultados, como afirma Sartori (2013, p. 233):

\footnotetext{
O que se pode esperar minimamente, é que o processo formativo inquiete os protagonistas do processo de ensino-aprendizagem, tornando-os professores mais comprometidos com o fazer do seu oficio. O aperfeiçoamento profissional, então apresenta-se como esperança de provocar transformação no horizonte daqueles que se desafiam e se lançam à tarefa de tentar modificar a realidade educacional e consequentemente, a realidade social.
}

Muitos afirmam que a interdisciplinaridade ocorre e sempre ocorreu nas séries iniciais, provavelmente este equívoco se dê ao fato de contar com a atuação de um docente, o que facilita a integração dos componentes curriculares. Entretanto, alguns não agem de forma interdisciplinar, ainda trabalham os componentes curriculares de forma fragmentada, não garantindo a construção do conhecimento de forma global, a qual é defendida também no PCN (2002, p. 88):

\footnotetext{
A interdisciplinaridade supõe um eixo integrador, que pode ser o objeto de conhecimento, um projeto de investigação, um plano de intervenção. Nesse sentido, ela deve partir da necessidade sentida pelas escolas, professores e alunos de explicar, compreender, intervir, mudar, prever, algo que desafia uma disciplina isolada e atrai a atenção de mais de um olhar, talvez vários.
}

Os cadernos disponibilizados para os professores abordam conteúdos específicos de português e matemática, mas no caderno de apresentação do programa, é possível perceber a preocupação em tornar os professores interdisciplinares. No PNAIC $(2013$, p. 19) pode-se encontrar a seguinte referência:

\footnotetext{
No caso dos projetos e das sequências, conhecimentos, habilidades e capacidades relativos a diferentes componentes curriculares são atendidos em um mesmo momento, em uma perspectiva interdisciplinar, em que seja constituída uma lógica de trabalho para além das disciplinas. Precisamos, para tanto, fortalecer o diálogo dos conhecimentos, naquilo que é possível, com as áreas, com os componentes curriculares, com os conteúdos, com as dimensões da vida: saúde; sexualidade; vida familiar e social; meio ambiente; trabalho; tecnologias e cultura.
}

Embora os cadernos não apresentem caminhos de como agir com interdisciplinaridade, os professores sentem que ela é necessária, pois a fragmentação dos conteúdos perdeu seu espaço no novo contexto da educação. É necessário direcionar sua prática pedagógica voltada para a flexibilidade, suas ações não podem ser definitivas, porque envolvem turmas heterogêneas, com sujeitos que podem reagir distintamente para mesmas situações.

Para assumir uma atitude interdisciplinar os docentes precisam abandonar a zona de conforto, os alunos não são meros expectadores, deixaram de ser passivos e buscam seu espaço dentro do ambiente escolar. A cada ano surge uma nova geração, a atual dispõe de tecnologias inovadoras e 
atrativas que não podem ser ignoradas, ao contrário precisam ser aproveitadas para construção dos conhecimentos propostos.

\section{O Lúdico no Espaço da Aprendizagem}

As atividades lúdicas estimulam as múltiplas inteligências, por isso o uso dessa metodologia é fundamental no processo de aprendizagem.

O cientista norte-americano Howard Gardner desenvolveu a Teoria das_Inteligências Múltiplas, descrevendo primeiramente as sete inteligências sendo elas: inteligência lingüística, musical, lógicomatemática, espacial, cinestésica, interpessoal e intrapessoal. Com referência à educação, Gardner afirma que a bagagem genética contribui para o desenvolvimento das inteligências, mas destaca que o aspecto biológico não é fator determinante, ou seja, o desenvolvimento das inteligências também é influenciado por fatores ambientais, é neste momento que se percebe a importância de ações pedagógicas que envolva e atraia o docente, para que as inteligências sejam estimuladas a fim de se alcançar o sucesso no processo ensino-aprendizagem, através de adaptações como diz Gardner (1994, p. 07):

\footnotetext{
A exata natureza e extensão de cada "estrutura" individual não é até o momento satisfatoriamente determinada, nem o número precioso de inteligências foi estabelecido. Pareceme, porém, estar cada vez mais difícil negar a convicção de que há pelo menos algumas inteligências e que estas são relativamente independentes uma das outras e que podem ser modeladas de maneira adaptativa por indivíduos e culturas.
}

A importância do lúdico foi bem destacada no Pacto Nacional pela Alfabetização na Idade Certa, salientando que estas práticas requerem um planejamento, pois sua importância não está só na diversão, mas também na aprendizagem que delas resultam, tais como: a expressão, a socialização, a comunicação etc.

O jogar e o brincar de maneira geral, promovem interações entre o grupo, assegura o levantamento de hipóteses, incentiva a investigação, estimula a curiosidade e a construção do pensamento que servem de alicerce para o desenvolvimento cognitivo, além de contribuir para a saúde física e emocional. O papel do professor é planejar estas práticas conforme as habilidades a serem desenvolvidas em cada fase, sabendo que é o mediador da formação de um cidadão participativo, autônomo e crítico.

\section{O Papel dos Pais no Acompanhamento dos Filhos em Relação à Educação}

A família têm se afastado da escola, provavelmente devido às mudanças ocorridas nos últimos tempos relacionadas a essa instituição. As mulheres hoje, além de cuidar dos filhos e da casa, também contribuem no sustento da família, e por vezes desempenham este papel sozinhas, dando surgimento dentre tantos outros, a mais um tipo de família contemporânea.

Existe uma cobrança da escola em relação à participação dos pais, principalmente para tratar da indisciplina dos alunos, os pais por sua vez estão atribuindo responsabilidades que são suas a escola. A partir destas divergências podem surgir conflitos, por isso é importante esclarecer os direitos e deveres de cada um. 
A Constituição Federal, no Art. 205, considera a educação, direito de todos e dever do Estado e da família, será promovida e incentivada com a colaboração da sociedade, visando ao pleno desenvolvimento da pessoa, seu preparo para o exercício da cidadania e sua qualificação para o trabalho.

A LDB (1996), no artigo 12, Parágrafo VII, destaca a incumbência da escola de informar pai e mãe, conviventes ou não com seus filhos, e, se for o caso, os responsáveis legais, sobre a frequência e rendimento dos alunos, bem como sobre a execução da proposta pedagógica da escola.

A partir destas colocações é possível observar que a lei sugere uma cumplicidade em prol do educando, à escola cabe incentivar e permitir a participação dos pais na vida escolar dos alunos, mesmo daqueles pais mais críticos, que fazem cobranças, pois estas podem estar atreladas a falta de conhecimento, indicando a necessidade do diálogo entre as partes.

Em relação às metodologias inovadoras praticadas por alguns professores, muitos pais criticam, são conteúdistas, provavelmente aprenderam desta forma, não participavam, só reproduziam, ou seja, eram imitadores. Muitos pais ainda não perceberam que a qualidade é mais importante que a quantidade. A escola deve cumprir com o papel de levar esta informação à família, destacando a importância de ações que contemplam o lúdico e a interdisciplinaridade.

É importante destacar que o PNAIC, também sugere ações voltadas para projetos, e estes estão diretamente relacionados com o lúdico e com a interdisciplinaridade, pois esta metodologia traz vantagens tanto para o professor como para os alunos, pois aprendem juntos. O projeto parte de um questionamento, e a busca pela resposta requer investigação, envolvimento de todo o grupo, o que resulta em debates, discussões que enriquecem e contribuem para o aprendizado.

Partindo do pressuposto de que a aplicação de projetos requer o uso de recursos didáticos diferentes, o espaço de aprendizado deixa de ser somente a sala de aula, outros ambientes, outros objetos, passam a ser explorados. O apoio dos pais para a utilização dessa metodologia é essencial. É necessário que os pais compreendam que através de projetos as aulas tornam-se mais prazerosas e produtivas, resultando numa melhor compreensão. Assim, os alunos transformam-se em sujeitos ativos, constroem pensamentos críticos, deixando de ser meros receptores, para se tornarem protagonistas de suas histórias.

\section{METODOLOGIA}

Os aspectos metodológicos que orientaram este estudo são apresentados a seguir, através da Caracterização da Pesquisa; A População e a Amostra; e A Coleta de dados e Análise de Conteúdo.

\section{Caracterização da Pesquisa}

Este estudo pode ser compreendido como um estudo de caso desenvolvido na Escola Estadual de Ensino Médio João Pedro Nunes, pois segundo Gil (2008) o estudo de caso consiste no estudo profundo e exaustivo de um ou poucos objetivos, de maneira que permita seu amplo e detalhado conhecimento. No entanto, os propósitos do estudo de caso não são os de proporcionar o conhecimento 
preciso das características de uma população, mas sim o de proporcionar uma visão global do problema ou de identificar possíveis fatores que o influenciam ou são por ele influenciados. (GIL, 2002)

Por serem analisados qualitativamente, os dados coletados neste estudo se caracterizam também como um estudo exploratório- descritivo.

Para Marconi e Lakatos (2009), estudos exploratórios-descritivos têm por finalidade a descrição completa de determinado fenômeno, o qual pode ser, por exemplo, um estudo de caso. As descrições oriundas da pesquisa exploratória-descritiva podem ser qualitativas e/ou quantitativas. Neste tipo de estudo, são realizadas análises empíricas e teóricas. Podem ser encontradas tanto descrições quantitativas e/ou qualitativas, quanto de informações detalhadas obtidas por intermédio de observação participante.

A pesquisa qualitativa revela áreas de consenso, tanto positivo quanto negativo, nos padrões de respostas. Ela também determina quais ideias geram uma forte reação emocional. Além disso, é especialmente útil em situações que envolvem desenvolvimento e aperfeiçoamento de novas ideias (MORESI, 2003). Avaliada como adequada para o entendimento dos assuntos aqui propostos, isto é, os desafios da prática do Pacto Nacional pela Idade Certa.

\section{População e Amostra}

A população desta pesquisa foi composta pelos professores e pais dos alunos dos três primeiros anos do ensino fundamental da Escola de Ensino Médio João Pedro Nunes na cidade de São GabrielRS, o que resultou em 05 professores e 24 pais entrevistados. Todos importantes por suas informações referentes a este estudo.

\section{Coleta e Análise dos Dados}

A coleta de dados foi realizada a partir de entrevistas semi estruturadas e um questionário com perguntas objetivas aos pais, realizadas durante os meses de Março a Agosto de 2015, foi embasada em materiais bibliográficos disponíveis no site do MEC, dentre eles os cadernos de alfabetização em língua portuguesa, matemática e educação especial. Aos professores e ao supervisor do turno da manhã, foi aplicado um questionário contendo perguntas discursivas com referências a não retenção, interdisciplinaridade, ludicidade e a participação da família na vida escolar do aluno.

A Escola Estadual de Ensino Médio João Pedro Nunes contempla o ensino fundamental e médio, é a maior escola estadual do município de São Gabriel, RS, tanto em número de alunos quanto de professores. O ensino fundamental possui seis turmas do $1^{\circ}$ ao $3^{\circ}$ Ano, com um professor regente em cada uma. No turno da manhã, no $1^{\text {o }}$ Ano estão matriculados 21 alunos, no $2^{\circ}$ Ano 22 alunos e no $3^{\circ} 25$. O turno da tarde encontra-se assim distribuído: o $1^{\circ}$ Ano com 24 alunos, $2^{\circ}$ Ano com 23, e o $3^{\circ}$ ano com 27 alunos. Foram distribuídos seis questionários aos professores, dos quais cinco foram respondidos, dentre os professores que responderam três professores participaram da formação do Pacto Nacional pela Alfabetização na Idade Certa.

Aos 24 pais entrevistados, no dia 20 de Agosto foi entregue um questionário com cinco perguntas objetivas, a primeira sobre a frequência que participam das reuniões na escola, a segunda se já haviam escutado falar sobre interdisciplinaridade, a terceira sobre a retenção, a quarta foi com referência aquele 
professor que passa muito conteúdo no quadro e a ultima foi uma avaliação de métodos de aprendizagem que envolvem jogos e brincadeiras.

A fim de aproximar a família e a escola, foi apresentada uma palestra abordando os assuntos desta pesquisa, pois foi percebido através das entrevistas e questionário que eles geram muitas dúvidas aos pais. Foram enviados 142 convites, ela foi realizada num dia letivo, às 18h30min, a fim de não atrapalhar a família na questão do horário de trabalho e do lazer.

Os dados da pesquisa foram analisados com base na análise de conteúdo das falas dos entrevistados, agrupadas a partir das respostas semelhantes. Na pesquisa qualitativa, a análise de conteúdo é a maneira mais adequada para se analisar os dados.

Segundo Godoy (1995): “a pesquisa qualitativa não procura enumerar e/ou medir os eventos estudados, nem emprega instrumental estatístico na análise dos dados. Parte de questões ou focos de interesses amplos, que vão se definindo à medida que o estudo se desenvolve."

\section{ANÁLISE E RESULTADOS}

Em relação a não retenção, a apreensão dos professores é visível e está relacionada ao sentimento do aluno no momento da percepção de que não conseguirá acompanhar os demais por não estar alfabetizado ou no mesmo nível de aprendizado. Alguns dos entrevistados se referiram a uma educação excludente, visto que a maioria é aluno de inclusão, e segundo eles, se continuarem sem retenção, num dado momento o fato de não acompanhar seus pares no processo ensino-aprendizagem, poderá levá-lo a desmotivação e consequentemente a evasão.

Ao longo das entrevistas e com base nas respostas obtidas através do questionário, acredita-se que alguns destes professores necessitam rever as teorias que norteiam suas ações pedagógicas, mais especificamente a não retenção. É necessário identificar as conseqüências negativas que a retenção pode causar ao aluno, e desconsiderar as falácias de que a repetição de conteúdos contribui para o aprendizado, porque quando se fala em construção do conhecimento, tem que ser para todos de uma forma continua. Não existe ninguém que não aprende nada, então por que retroceder? Por que desconsiderar o que já se aprendeu?

O PNAIC apresenta no seu caderno voltado para a Educação Inclusiva, um parágrafo relacionado às diferenças, iniciando com o seguinte questionamento:

\footnotetext{
O que fazer com a diferença? É preciso pensá-la sem fazer comparação com "algo". A diferença aqui não deve nos levar ao que se discute no caderno de Grandezas e Medidas, não se trata de estabelecer um padrão comum, não se trata de classificar e hierarquizar... O desafio é pensar a diferença como parte ativa da identidade das pessoas que por ela ou através dela não se tornam nem melhores e nem piores, nem superiores nem inferiores, elas se tornam "apenas" o que são e nós convivemos com elas como nós somos e como elas são. Este é o sentido afirmativo de conviver (ou viver) com a diferença. PNAIC (2014, p. 9)
}

Não existe homogeneidade numa turma, talvez com a compreensão de que ninguém é igual, e que todo o saber tem seu valor, torne a não retenção um desafio vencido, por estes docentes. 
No que se refere à interdisciplinaridade, percebeu-se que todos os docentes participantes apreciam esta prática, mas nota-se que alguns são, outros estão interdisciplinares. Ser é uma atitude, é ser sempre, suas práticas pedagógicas estão direcionadas para um conhecimento globalizado, enquanto estar é um momento, eventualmente se estabelece um elo entre as disciplinas e a integração de um conteúdo com outras áreas de conhecimento.

Na opinião de um dos entrevistados, ser interdisciplinar exige uma nova postura, é interagir com o aluno diante da perspectiva de construir conhecimentos a partir dos saberes de ambos, sem deixar de cumprir as metas estabelecidas no seu plano de trabalho, como também assegura Sartori (2013, p. 186):

\footnotetext{
O ato de dialogar facilita a reflexão sobre as práticas, possibilitando o replanejamento e/ou dar continuidade ao processo, conforme as manifestações do aluno em relação ao seu aprendizado. A abordagem dos conteúdos escolares, ao serem desenvolvidos no horizonte de uma atitude interdisciplinar, não surge do mero acaso; origina-se da decisão e da vontade política construída, tanto no nível pessoal como no grupo de professores da escola. É certo que esse intento, ponderando o longo histórico de práticas disciplinares e fragmentadas do cotidiano escolar, necessita de paciência e persistência até que se assuma a atitude interdisciplinar como uma forma de praticar, refletir, reordenar e desenvolver a prática pedagógica.
}

Em relação à ludicidade, percebeu-se que todos os pesquisados apóiam esta prática, e vêem na estrutura física da escola um aspecto positivo para isso. Entretanto, um professor destaca que a indisciplina dos alunos, a extensa relação de conteúdos e a falta de tempo, por vezes atrapalham esta prática. Estas dificuldades possivelmente estão atreladas a falta de uma reorganização pedagógica, visto que o termo flexibilidade é considerado pelo PNAIC, pelo Projeto Político Pedagógico da referida escola, bem como na introdução dos PCNs (1997, p. 53) que faz a seguinte referência:

\footnotetext{
Considerar conteúdos procedimentais e atitudinais como conteúdos do mesmo nível que os conceituais não implica aumento na quantidade de conteúdos a serem trabalhados porque eles já estão presentes no dia-a-dia da sala de aula, o que acontece é que, na maioria das vezes não estão explicitados, nem são tratados de maneira consciente. A natureza dos conteúdos escolares deve ser contemplada de maneira integrada no processo de ensino aprendizagem e não em atividades específicas.
}

Já em relação à indisciplina dos discentes indicada como empecilho na sua prática, acredita-se que pode estar relacionada com a recusa por parte do docente de adaptar-se a estas mudanças tecnológicas que vem ocorrendo, por isso a fim de acompanhar estas mudanças aceleradas, considerase importante a busca da ressignificação de práticas por parte dos docentes, o que é corroborado com colocação de Sartori (2013, p.210) quando diz:

O mundo contemporâneo exige cada vez mais fortemente das pessoas aquilo que não se exigiu em outros momentos da história da humanidade: envolver-se na crítica e na reinvenção do conhecimento de forma a, efetivamente, contribuir para o desenvolvimento sócio-histórico, mediante o redimensionamento dos modos de viver e conviver e o aprimoramento do exercício profissional.

Com relação à participação dos pais, observou-se que os professores a consideram de extrema importância, e que na medida do possível tentam levar os esclarecimentos a respeito do aprendizado dos seus alunos, mesmo aqueles pais que não se fazem presentes quando solicitados. Entretanto, os 
professores revelaram a necessidade de uma maior participação dos pais na vida escolar de seus filhos. Nesse intuito, foi desenvolvida uma palestra a fim de promover a aproximação dos pais e a escola, abordando os desafios enfrentados pelos professores e os assuntos que geram muitas dúvidas aos pais, principalmente no que se refere a não retenção. Infelizmente, não houve comparecimento dos pais, isso confirma que a família não tem mais tempo para seus filhos e justificam esta ausência pela necessidade do trabalho.

\section{CONSIDERAÇÕES FINAIS}

Após muitas mudanças no sistema do ensino brasileiro, principalmente com referência a métodos de alfabetização, acredita-se que o PNAIC, poderá melhorar os índices da educação, se suas orientações forem colocadas em prática, principalmente na parte que tange a formação continuada para os professores.

Em relação aos desafios referentes à interdisciplinaridade e ludicidade, percebe-se a necessidade de uma revisão teórica por parte dos docentes, traçando um paralelo dos contextos históricos que estão inseridos. O tempo e a indisciplina de alunos citados como barreiras, por alguns professores, podem ser uma máscara para a resistência ao uso destas metodologias, talvez pela falta de uma "receita" para sua aplicabilidade. Por isso acredita-se que estas práticas devem ser incentivadas na graduação e também na formação continuada, porque alguns professores atuantes estão condicionados a velhos métodos que foram suficientes para o seu aprendizado. São ditas frase como "eu aprendi assim, por que mudar"? Este individualismo precisa ser superado a partir da conscientização de que as vivências e experiências trazidas pelo aluno precisam ser consideradas, pois contribuem na construção do conhecimento, e isto cabe principalmente nas séries iniciais em que as crianças estão descobrindo-se como sujeitos da sua educação.

O desafio maior constatado nesta pesquisa caracteriza-se pela não retenção. As diferenças estão presentes em todas as turmas, e acredita-se que o caminho para atingir o sucesso no aprendizado é a aplicabilidade constante do lúdico, visto que esta é uma prática que agrada a todos e é vista por muitos pesquisadores como um complemento essencial no desenvolvimento das crianças. Em relação ao sentimento dos que apresentam dificuldades na aprendizagem, isto não deve ser motivo de inquietação, pois não se pode esquecer que este processo deve ser continuo para todos, não se desconstrói um conhecimento, todos os saberes tem seu valor e as conseqüências do reter podem ser mais graves do que não reter.

Diante deste desafio é necessário refletir sobre a orientação do PNAIC, onde diz que nas escolas, infelizmente, é comum que documentos que contenham diagnósticos médicos sirvam para justificar a falta de ação (da escola e do professor) em relação ao aluno: isso ocorre quando o professor alega não se sentir preparado para o ensino de alunos com deficiência. Casos assim deveriam ser entendidos como ponto de partida para um trabalho de cunho educacional de cunho educacional e pedagógico destinado a esses alunos, e não o final do processo de escolarização para eles. Quando isso ocorre é como se a escola estivesse dizendo: estes não são capazes de aprender, desistimos!

Em relação à participação da família na vida escolar dos discentes, é necessário que a escola articule com os docentes, estratégias para que os pais cumpram com seu papel de educar, e participem 
quando convidados para tratar de assuntos dos seus interesses. Assim, o aluno se sentirá seguro, sabendo que alguém se preocupa com sua formação, com seu dia-a-dia. Muitos pais estão atribuindo a função de educar para a escola, ou seja, estão confundindo educação com escolarização, é necessário que compreendam que a educação forma as pessoas, é a partir dela que se constroem os valores sociais, já a escola contribui neste processo, mas é responsável pela construção do conhecimento.

Como recomendação para a Escola estudada, em síntese, sugere-se que algumas práticas sejam revistas e até mesmo que sejam propostas mais atividades de capacitação e treinamento para os professores abrangendo os temas interdisciplinaridade e ludicidade. A capacitação é necessária para que estes consigam trabalhar de forma mais eficiente com alunos que apresentam algum tipo de problema e/ou deficiência relacionada à aprendizagem e também para que compreendam que a retenção, pode prejudicar o processo ensino-aprendizagem que deve ser continuo para todos. Este é um fator importantíssimo a ser vencido por parte de alguns professores entrevistados.

\section{REFERÊNCIAS BIBLIOGRÁFICAS}

ANTUNES, Celso. As inteligências múltiplas e seus estímulos. Campinas: Papirus, 2000.

BRASIL. Constituição Federal da República. Brasília: Presidência da República, 1988.

BRASIL. Ministério de Educação e Cultura. LDB - Lei no 9394/96, de 20 de dezembro de 1996. Estabelece as diretrizes e bases da Educação Nacional. Brasília: MEC, 1996.

BRASIL. PCN - Parâmetro Curricular Nacional da Língua Portuguesa. Brasília: MEC, 1997.

BRASIL. Secretaria de Educação Fundamental. Parâmetros curriculares nacionais: introdução aos Parâmetros Curriculares Nacionais/Secretaria de Educação Fundamental. Brasília: MEC/SEF, 1997. 126p.

GARDNER, Howard. Estruturas da mente: a Teoria das Múltiplas Inteligências. Porto Alegre: Artes Médicas, 1994.

GIL, Antonio Carlos. Como elaborar projetos de pesquisa. São Paulo: Atlas, 2002.

GIL, Antonio Carlos. Como elaborar projetos de pesquisa. São Paulo: Atlas, 2008.

GODOY A.S.(1995).Introdução à pesquisa qualitativa e suas possibilidades. Revista de Administração de Empresas.

http://pacto.mec.gov.br/index.php Acesso em 20/07/2015

http://portalsme.prefeitura.sp.gov.br/Documentos/pme/Entendendo_Pacto.pdf. Acesso em 21/08/2015

http://www.direcionaleducador.com.br/edicao-80-set/11/reprovacao-escolar-uma-questao-muitas-facetas. Acesso em 22/08/2015.

http://citacoesacademicas.blogspot.com.br/2011/08/interdisciplinaridade-parametros.html. Acesso em 22/08/2015 MARCONI, Marina de Andrade; LAKATOS, Eva Maria. Fundamentos de metodologia científica. São Paulo: Atlas, 2009.

MARQUES, Vera Regina Beltrão. História da Educação. Curitiba: IESDE Brasil, 2008.

Ministério da Educação, Secretaria de Educação Básica. Pacto nacional pela alfabetização na idade certa: formação de professores no pacto nacional pacto nacional pela alfabetização na idade certa. Brasília: MEC-SEB, 2012.

MORESI, E. (Organizador), Metodologia de Pesquisa. Universidade Católica de Brasília, 2003

SARTORI, Jerônimo. Formação do professor em serviço. Da (re)construção teórica e da ressignificação da prática. Passo Fundo. UPF, 2013. 